\title{
The efficacy of permethrin-treated military uniforms as a personal protection against Culex pipiens (Diptera: Culicidae) and its environmental consequences
}

\author{
${ }^{1 *}$ M. Khoobdel, ${ }^{1}$ M. Shayeghi, ${ }^{1}$ H. Ladonni, ${ }^{2} Y$. Rassi, ${ }^{2}$ H. Vatandoost, ${ }^{2}$ H. Kasheffi Alipour \\ ${ }^{1}$ Department of Medical Entomology, School of Public Health and Institute of Health Research Center, \\ Tehran University of Medical Science, Tehran, Iran \\ ${ }^{2}$ Military Health Research Center, Military Medicine Institute, Baqiyatallah University of Medical Sciences, \\ Tehran, Iran
}

\begin{abstract}
Naturally, there are different species of Culex mosquitoes in Iran. Culex pipiens complex is widespread in many parts of the country, specially in urban areas. In spite of this fact that $C x$. pipiens species is the vector of some orboviruses and filariasis in many countries of the World, it does not have an important role in transmission of diseases in Iran. This species can easily reproduce in urban areas, due to the infection of surface waters and presence of sewage canals. The importance of Cx.pipiens for mankind is in fact, its biting and nuisance, specially at sleeping time. In this study, six types of current military uniforms of Iran's army were treated by permethrin $\left(0.125 \mathrm{mg}\right.$. permethrin [AI] $\left./ \mathrm{cm}^{2}\right)$ and examined against the biting of natural population of Cx.pipiens in urban areas in Tehran. Eight volunteer were selected for this study. Six of them put on the treated uniforms and the other two of them wore the untreated uniforms. All the subjects participated in the night biting test for eight active nights July 2004. There was no significant difference in the protection of different treated uniforms against mosquitoes biting. The average number of biting among who wore untreated uniforms (control) was 2.14 mosquito biting/min/person (128.2/hr), While it was 0.23 (13.8/hr) for who wore treated uniforms. The percent protection of treated uniforms, in comparison with untreated ones, was about $89 \%$. The protection percent of treated uniforms for different species of mosquitoes, in comparison with untreated ones, was calculated through determining the species of captured mosquitoes, separately from case and control subjects. The results of species identification among captured mosquitoes of a field study showed that about 95\% of them are of Cx.pipiens species, and protection of treated uniforms against them, was estimated 87\%. Moreover, as an accompaning environmental consequence a significant reduction in mosquito’s density was seen.
\end{abstract}

Key words: Permethrin, Culex pipiens, mosquitoes, environmental consequences, impregnation, HPTLC

*Corresponding Author, E-mail: khoobdel@yahoo.com

\section{Introduction}

Culex mosquitoes are involved in transmitting some arboviruses disease, such as; viral encephalitis and lymphatic fillariasis. Cx.pipiens species is also vector of some diseases including West Nile fever, Rift Valley fever, and also some lymphatic filariasis (Harbach, et al., 1988; Barnard, et al., 2004).

Culex or house mosquito enters places in different ways and nuisance indivuals, especially at night. Besides, Culex biting causes problems like itching, burning, and inflammation among sensitive persons, especially children. Cx.pipiens bites human indoor, as well as outdoor, mainly at sunset and night (Savage, et al., 1995). During the eight years imposed war of Iraq against Iran, Culex mosquito's nuisance Iranian soldiers too much, in south and south west of Iran in war zones. At that time, a kind of insect repellent, called "Trench Pomade" (a mixture of DEET + DMP), was widely used for protecting military personnel, which had a satisfactory results (Mehrabi Tavana, et al., 2001).

Personnel of military forces have close contact with the environment and can be bitten by insects and exposed to the related diseases, more than other people (Schreck, 1977; Debboun, et al., 2001). In recent years, progresses have been occurred in protecting people, especially military personnel, against arthropod bites and vector-borne disease, using repellents, and treating tents, mosquito nets and clothes with insecticides (Debboun, et al., 2001). Treating mosquito nets, tents, curtains, blankets, and clothes with Pyrethroid, has become current since many years ago. Allowed doses of permethrin, is believed to be a safe repellent and insecticide so, it has been widely used for treating military uniforms and has protected them against hematophagous arthropods like mosquitoes, ticks, mites, fleas, and 
many other insects (Frayauff, et al., 1996). Using permethrin-treated military uniforms in its allowed and safe doses $\left(0.125 \mathrm{mg} / \mathrm{cm}^{2}\right)$ has been known as an effective method for protecting military personnel against hematophagous insects (Schreck, et al., 1978, 1980; Sholdt, et al., 1988; Lane, et al., 1984 and Anderson, et al., 1984). Several laboratory and field researches have been done in many armies of the world to evaluate the effectiveness of permethrin treated uniforms; the results have been satisfactory in most cases (Lillie, et al., 1988; Ansari, et al., 1998 and Esmsila, et al., 1994).

Today, using permethrin-treated military uniforms is among the hygienic programs of many armies of the world, and the U.S army widely used these clothes in Persian Gulf war (Magill, et al., 1993). Using permethrin-treated uniforms has also been introduced in some countries like France, as a vector control strategy and protection method for military personnel against insects (Deparis, et al., 2001).

In this study which has been performed for the first time in Iran, the protection of permethrin-treated military uniforms against $C x$.pipiens in a urban field has been examined. The study indicated that permthrin-treated military uniform are effective against mosquitoes' biting. This study has been done in the north of Tehran, on 2004.

\section{Materials and Methods}

\section{Study sites and volunteers}

Cx.pipiens is an urban species, which mainly lays eggs in infected waters and sewage's, and thus, is abundant in urban areas. For this reason, the study was performed in a house, north of Tehran. The house had a big yard and garden $\left(750 \mathrm{~m}^{2}\right)$, with fruit trees and a relatively big pool with left over and dirty water, it was an appropriate place for laying and breeding of Culex mosquitoes. Before the survey, a pilot study was performed in the site (house) and it was as an appropriate place for bioassay test (night biting) due to the abundance of Cx.pipiens mosquitoes and biting pressure. Base on the EPA standard, at least 5 biting per 5 minutes acceptable for mosquitoes test.

Eight male subjects were selected for wearing permethrin-treated and untreated uniforms (six as cases and two as controls). In order to decrease subject caused errors, they wore the uniforms in a revolving manner (subjects in eight nights wore all treated and untreated uniforms). Subjects were 1925 years old, and their age average was 20.8 years. Eight officers were also appointed as collectors. The subjects were trained about the test time and the needed activities. The officers were also trained about the method of data registration in special sheets.

\section{Treating uniforms}

For this study, six types of the military uniforms, which had been worn, were selected. Then, the physical specifications of uniforms such as water absorption coefficient, quality of materials fiber, and weight and area of each uniform were determined. The fiber of uniforms consisted of cotton-polyester and nylon, with different ratio. These uniforms were treated at rate of $0.125 \mathrm{mg}$. active ingredient (AI)/ $\mathrm{cm}^{2}$ of cloth with aqueous suspensions of permethrin from $10 \%$ emulsifiable concentration (EC) formulation (cis/trans isomers with 25\% / 75\% ration respectively). The concentrations of treating solutions of permethrin were determined based on the quality and absorption coefficient of six uniforms' textile and also the area of uniforms. Then, treating was done by dipping method. Sufficient liquid (450-500 $\mathrm{ml}$.) was used to saturate each article of clothing without runoff. Saturated fabrics were placed in plastic bags for $24 \mathrm{~h}$. to enhance liquid penetration. The uniforms were then removed from the bags, placed horizontally on aluminum foil and turned periodically to air dry without loss of permethrin from dripping. Before testing, the clothing was labeled and stored in fresh plastic bags (Schreck, et al., 1980). The control uniforms were treated just by water. The uniforms were kept in laboratory condition (temperature: $23-26^{\circ} \mathrm{C}$, relative humidity: 30-40\%). For assuring to achieve a deposition rate of $0.125 \mathrm{mg}(\mathrm{AI}) / \mathrm{cm}^{2}$ of fabrics, three to four $2 \mathrm{~cm}^{2}$ pieces of uniform's textile from pockets and collars were cut and separately put in small vials. After sealing the vials by parafilm, they were kept in $8^{\circ} \mathrm{C}$ temperature. Before starting field test, their permethrin were extracted and measured by HPTLC technique.

\section{Field test}

After primary reviews, the subjects were selected and trained about the test. They were asked not to use insect repellent or attractive materials like perfumes, alcohol, smoke, garlic, mint and other odorous materials. Subjects received the uniforms, half an hour before sunset. Six of subjects wore the treated uniforms and the other two ones, wore the control untreated uniforms. Subjects sat in appropriate distance of each other (10 meters). The 
control subjects sat in the same manner, in 40-50 meters distance of case subjects.

Field test was started at sun set. One collector was considered for each subject. The collectors entered the night biting data in the sheets. The mosquitoes collected with the help of a mouth aspirator and flashlight (hand catch method) and placed into separate cups for subsequent identification. The mosquitoes that only landed were just counted and not captured. The related collector and officer determined the subgenus of mosquitoes (Anophelinae or Culicinae). The cups were changed every half an hour, in order to calculation of the activity peak of mosquitoes. Meanwhile, subjects changed there place every half an hour to face the untried mosquitoes and prevent a fatigue or knockdown effect on mosquitoes because of repeated contacts with treated uniforms in the same areas (Schreck, et al., 1989).

Night biting test was started at 20:00 and ended at 1:00 every night, when number of bitings decreased. The subjects ate their dinner before starting the test and didn't have any activity during the test, except a 15 minute rest at 11:30, when the bitings had a decrease. Temperature and percentage of relative humidity were recored at the beginning and end of each 1-h exposure period. After ending the test every night, the uniforms were collected and given back to the subjects, the next night.

\section{Chemical analysis}

Two $\mathrm{cm}^{2}$ pieces of uniforms were cut before and after the field test, and kept at $8^{\circ} \mathrm{C}$ for assuring of the treating confidency and also determining the remained permethrin in the uniforms. One-ml pure acetone was added to the vials containing $2 \mathrm{~cm}^{2}$ pieces of uniforms. The vials were sealed and the permethrin of uniform pieces was extracted by 10 minutes shaking and then allowed to stand 1 hour just before analysis to ensure extraction of a representative quantity of permethrin (Schreck, et al., 1982). The spotting on a silica gel containing aluminum plate, was performed by an applicator and capillary.Volume of each spot was $10 \mu \mathrm{l}$. and the distance between spots was $1 \mathrm{~cm}$. The standard permethrin $(10 \mathrm{mg}$.$) was purchased from$ Accustandard Company. For spotting the samples, the multiple level method was used. In this method, some different concentrations or different volumes of a standars concentration are used for spotting the standard sample. After spotting and drying the spots, the ready plate is put inside the chamber tank.
The mobile phase solvent used for permethrin, was n-hexane-ethyl acetate (Chen, et al., 1996; Sherma, 1997; Lee, et al., 1998; Gupta, et al., 1998). This was poured into the tank and the ready plate was put in it after saturation of tank. Then, plate was exited of the tank. After drying, spots were observed in UV cabinet by florescence light with $254 \mathrm{~nm}$. wavelength. Finally, the spots were scanned by TLC Scanner 3 (CAMAG), using CATS4 software, (the measurement mode was Absorption / Reflection, $\lambda=207 \mathrm{~nm})$.

\section{Species identification}

The mounted mosquitoes were identified in laboratory, using valid identification keys (Zaim and Cranston, 1986; Harbach, 1988).

\section{Data analysis}

Data were set and standardized based on the number of bitings per minute, for each subject. Since the statistical analysis of this study was done bases on the quantity, data was firstly transferred by $\sqrt{y+0.5}$ equation (y: number of bitings per minute) and then poisson distribution was used for statistical analysis of bitings number in case and control groups. For comparing the biting means (on skin and through uniforms) in subjects who had worn 6 types of military uniforms, analysis of variances (ANOVA) and Tukey method were used for multiple comparison. For comparing the means of biting and landing (on skin and through uniforms) in treated and untreated groups, T-test was used. After statistical analysis, the means retransformed to original units and converted to mosquito bites per minute. Protection percent of treated uniforms was calculated using the following equation:

Protection percent $=\frac{\text { untreated biting }- \text { treated biting }}{\text { untreated biting }} \times 100$

\section{Results}

In this study, 6 types of military uniforms with different percents of cotton, polyester and nylon fibers, all treated by $0.125 \mathrm{mg} / \mathrm{cm}^{2}$ permethrin, were compared together. The results showed that in spite of the differences in fiber type, water absorption coefficient, thickness, light stability and some other physical factors of uniforms, there was not a significant differences in protection percent of 6 types of uniforms $(p>0.05)$. The mean of biting per person for all treated uniforms was 13.8 per hour $(\mathrm{SE}= \pm 1.30)$. Comparison of treated and untreated 
uniforms showed that the protection percent of treated uniforms against mosquito biting was totally $89 \%$, which was significantly higher than untreated uniforms $(\mathrm{P}=0.002)$. The mean of biting per percent for untreated uniforms was $128.2(\mathrm{SE}= \pm 6.13$ ) per hour (Table 1). Natural population of mosquitoes in this study was mainly $C x$. pipiens. This species usually bite at nights and through skin.

Since they rarely bite through clothes, more than $95 \%$ of bitings in this study occurred through skin.

Table 1: Mean of mosquito bites per person, in 6 kinds of Iranian military uniforms (treated and untreated)

\begin{tabular}{|ccccc|}
\hline Uniforms & $\begin{array}{c}\text { Mean bites per } \\
\text { hour }\end{array}$ & SD & $\begin{array}{c}\text { SE of } \\
\text { mean }\end{array}$ \\
\hline \multirow{6}{*}{ Treated } & $\mathrm{U}_{1}$ & 12.1 & 2.25 & 0.56 \\
& $\mathrm{U}_{2}$ & 17.7 & 8.80 & 2.20 \\
& $\mathrm{U}_{3}$ & 9.8 & 2.27 & 0.57 \\
& $\mathrm{U}_{4}$ & 10.0 & 1.85 & 0.40 \\
& $\mathrm{U}_{5}$ & 20.6 & 11.07 & 2.77 \\
& $\mathrm{U}_{6}$ & 12.6 & 5.15 & 1.29 \\
\hline Untreated & $\mathrm{U}_{0}{ }^{*}$ & 128.2 & 24.51 & 6.13 \\
\hline
\end{tabular}

Statistical analysis was performed on the squar-root transformation of number of mosquito bites per minute

* is significantly different $\mathrm{P}<0.01$. U: Uniforms

Table 2: Mean number of mosquito bites received per person per hour on exposed skin and through the clothing

\begin{tabular}{|ccccc|}
\hline \multirow{2}{*}{ Subject } & \multicolumn{3}{c}{ Mosquito bites per hour } & $\begin{array}{c}\text { Mosquito } \\
\text { landing } \\
\text { per hour }\end{array}$ \\
\cline { 2 - 5 } & On skin \pm SE & $\begin{array}{c}\text { Through } \\
\text { clothing }\end{array}$ & Overall & $\begin{array}{c}\text { Percent } \\
\text { protection }\end{array}$ \\
\hline Treated & $13.8 \pm 1.30$ & 0.0 & 13.8 & 89 \\
Untreated 128.2 \pm 6.13 & 0.31 & 129.5 & 0 \\
\hline
\end{tabular}

Comparison of the mean of bitings through skin in treated and untreated groups showed that there is a significant difference between them $(\mathrm{P}<0.01)$, (Table 2). This study was performed at the July. When the mosquitoes has maximum bite. Night biting activity of $C x$. pipiens in Tehran was also determined (Figure 1). The mean of air temperature during study and at different hours (20-01) was $26.6^{\circ} \mathrm{C}(19-30$ ${ }^{\circ} \mathrm{C}$ ) and the mean of relative humidity was $44 \%$ (33$58 \%$ ). As it is already mentioned, the collectors recorded all of bitings on subjects on sheets. Besides, the biting mosquitoes were captured by aspirator. Totally, $75 \%$ of mosquitoes, which bited case and control subjects, were captured.

Table 3: Percent protection of permethrin-impregnated military uniforms against $C x$. pipiens

\begin{tabular}{|lccc|}
\hline \multicolumn{4}{|c|}{ Captured on volunteers per night } \\
\hline Species & Untreatment & Treatment & $\begin{array}{c}\text { Percent } \\
\text { protection } \\
(\%)\end{array}$ \\
\hline Cx. pipiens & 213.3 & 28.7 & 87.00 \\
Cx. theileri & 2 & 0 & - \\
Culex.spp & 11.5 & 0.6 & - \\
\hline
\end{tabular}

Table 4: Thin layer chromatography analysis of the amount of permethrin remaining $\left(\mathrm{mg} / \mathrm{cm}^{2}\right)$ in treated uniforms $\left(0.125 \mathrm{mg} / \mathrm{cm}^{2}\right)$ at the start and end of filed test

\begin{tabular}{|lcc|}
\hline Status & Mean $\left(\mathrm{mg} / \mathrm{cm}^{2}\right)( \pm \mathrm{SE})$ & Range $\left(\mathrm{mg} / \mathrm{cm}^{2}\right)$ \\
\hline In the start & $0.126( \pm 2.27)$ & $0.115-0.129$ \\
In the end & $0.123( \pm 4.66)$ & $0.111-0.133$ \\
\hline
\end{tabular}

$\mathrm{R}_{\mathrm{f}}$ (trans) $=0.41$

$\mathrm{R}_{\mathrm{f}}(\mathrm{cis})=0.48$

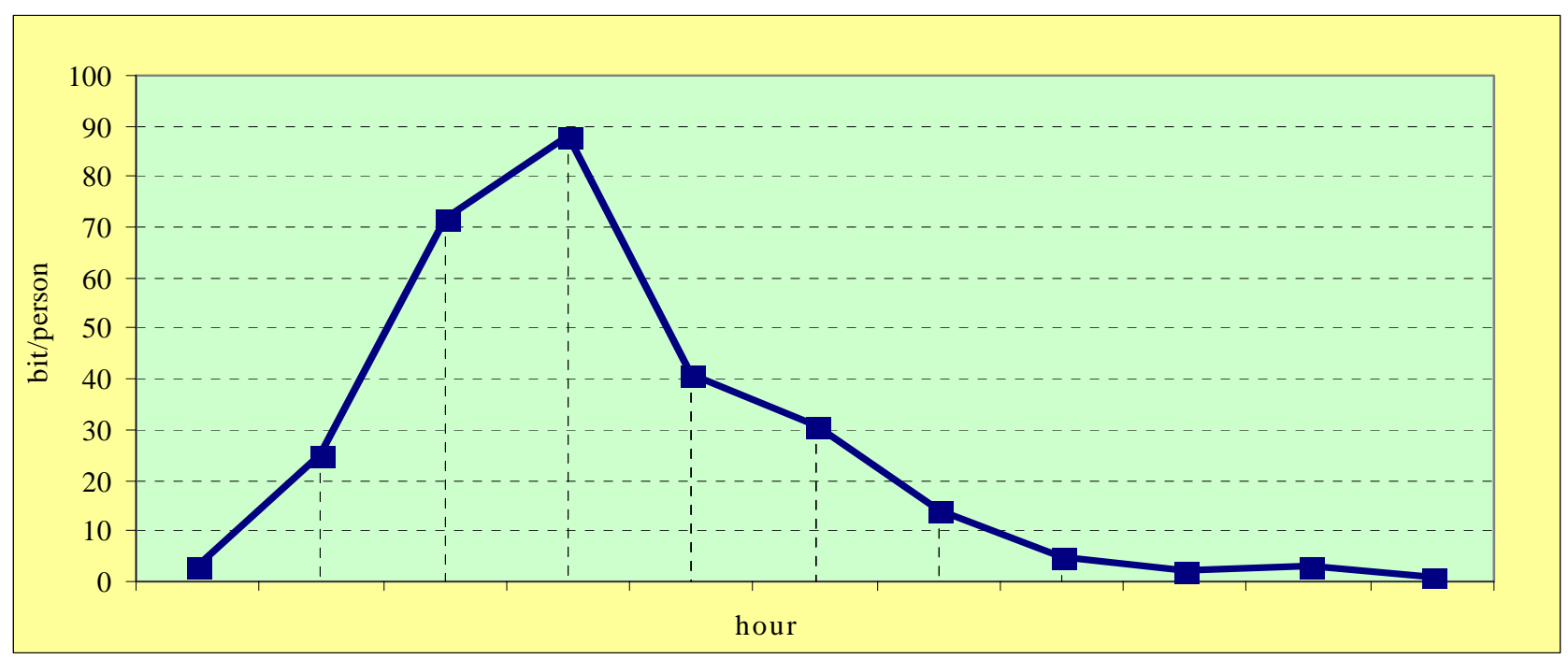

Figure 1: Night biting (bites/person) activity of Cx. pipiens in Tehran, 2-17 July 2004 
So, the protection percent of each mosquitoes species was calculated using the number of captured mosquitoes from case and control subjects. The results of this study showed that the protection of treated uniforms, in comparison with untreated ones, against $C x$. pipiens was $87 \%$ (Table 3 ).

In addition some other species of Culex namely $C x$. theileri, $C x$. spp were also captured during the study, but since their number were too low and their biting pressure were less than 5 biting per 5 minute, calculation of protection percent was impossible for them, even at the peak hour of their night biting activity. The results of chemical analysis by HPTLC method showed that the concentration of permethrin in different uniforms was $0.126 \mathrm{mg} / \mathrm{cm}^{2}(0.115$ 0.129 ) at the start of field test and $0.123 \mathrm{mg} / \mathrm{cm}^{2}$ (0.111-0.133) at the end of it (two weeks later), which was not significantly decrease $(\mathrm{P}>0.05)$. Two separate spots of trans-permethrin and cispermethrin were observed. $R_{f}$ value was also calculated for the two isomers (Table 4).

\section{Discussion and Conclusion}

Every kind of fiber has its own physical specifications, insecticide molecules may act differently in penetration and making physical bonds with them. This difference may appear immediately after treating. It has been shown in some studies that $\mathrm{LD}_{50}$ of permethrin-treated cotton fibers is three times more than Permethrin-treated nylon fibers (Hossain and Curtis, 1998). Differences of various fibers in retaining insecticidal quality after treating may appear with influence of some physical and environmental factors like washing, aging, rinsing, wearing and weathering. On the other hand, efficacy of fibers may be different by various insecticides. For example, efficacy of deltamethrin for treating cotton fibers is more than other pyrethroids, while efficacy of cyfluthrin on jute fibers is more than other insecticides. Efficacy of Lambdacyhalothrin, however, is similar on all fibers including cotton, Jute, nylon and polyester (Ansari, et al., 1998). Iranian military personnel use different uniforms, like many other countries of the world, that the quality of their fibers and many other physical specifications of them are different from each other. So, there may be some differences in penetration of insecticide in them and their protection. Although the study uniforms contained different percents of cotton and polyester fibers, and a small percent of nylon and other fibers, there was not a significant difference in their insecticidal quality $(\mathrm{P}>0.05)$. Meanwhile, there was not a significant difference in the remained amount of permethrin of different uniforms, three weeks after treating $(\mathrm{P}>0.05)$. But regarding to the variety of fibers of the six uniforms, environmental and physical factors may have different effects on them. In a similar study, the quality of fibers of two various treated textile (100\% cotton, and 50\% cotton - 50\% nylon) has been ineffective in their protection against mosquito biting, but environmental factors like weathering have been effective in this regard (Gupta, et al., 1989). New formulations of pyrethroid and other chemicals have been recently prepared that increases the lasting of insecticide on the fibers. For example, in Olyset Net, a strong bond is made between permethrin molecule and polyethylene fibers by a polymer that isn't broken even by frequent washing and sun light and heat (Gonzalez, et al., 2002). Also in Prema Net, deltamethrin insecticidal has been mixed by resin and made a bond around polyester fibers (WHO, 2000). So, insecticidal molecules gradually are released from polymer and resin and come to the surface. In this way, lasting of insecticides on fibers increases (Guillet, et al., 2001 and Guessan, et al., 2001).

Although most of laboratory studies have been reported $100 \%$ mortality of different species of mosquitoes in bioassays on permethrin-treated clothing (Schreck, et al., 1989; Romi, et al., 1997), but the results of field test and evaluation of permethrin-treated clothing is some different; so that in field studies, protection of permethrin-treated clothing against Culiseta impatients (Lilli, et al., 1988) and Aedes taeniorhynchus and Culex sitiens (Schreck, et al., 1989), have been reported 93\%, $99 \%$ and $43 \%$ respectively. In one other study in Pakistan, the mean Protection percent of permethrintreated uniforms against different species of mosquitoes has been estimated 57\% (Sholdt, et al., 1988). The protection of permethrin-treated military uniforms against $C x$.pipiens biting was also about $87 \%$ in the present study (Table 3).

The use of permethrin-treated military uniforms maybe to result in many environmetal consequences. For example in large number of military or civilian personal that worn this treated clothes and camped in a limited area can significantly reduce the mosquito density, although insecticide resistance might be occure. Permethrin residual resulting of washing of these clothes maybe release in to current and stagnant waters and contaminated them. This is hazardous for fishes and other aquatics. The reminde of permetrin solution through impregnation 
process should be lead in sewage that can be as a mosquito larvicide. On the other hand use of this technique in great scale, maybe reduce consuming of insecticiedes and consequently environmental contamination. Safety of permethrin-treated military uniforms was demonstrated (WHO, 2000). Finally, based on the results obtained here, using permethrin treated clothing should be a useful personal protection technique for Iranian soldiers, which makea a considerable protection against mosquitoes biting and if used with application of repellents on skin, provide the maximum protection.

\section{Acknowledgments}

The authors would like to thank Institute Health Research Institue, School of public health, Tehran University of Medical Sciences for their financial supports and Mr. Salehi who offerd his place for this study. Authors would also like to thank the volunteer, (M. Shah Mohammad, J. Shah Mohammad, A. Badakhshan, N. Badakhshan, E. Nezam, A. Omar Zaman, A. Molla Samie and V. Baran), Authors are also grateful to Dr. Bahrami and Mrs. Gobadi from Faculty of Textile Engineering, Amir Kabir University.

\section{References}

Ansari, M. A., N. Kapoor and V. P. Sharma, Relative efficacy of synthetic pyrethroid-impregnated fabrics against mosquitoes under laboratory conditions. $J$. AM. Mosq. Control. Assoc., 14 (4): 406-409, 1998

Barnard, D. R., Laboratory evaluation of mosquito repellent against Aedes albopictus, Culex nigripalpus and ochleratatus triseriatus (Diptera: Culicidae). J. Med. Entomol., 41 (4): 726-730, 2004

Chen, Z. M. and Y. H. Wang, Review chromatographic methods for the determination of pyrethrin and pyrethroid pesticide residues in corps, foods and environmental samples, J. Chromatogr., 754: 367395, 1996

Cupta, R. K., W. G. Rutledge, G. A. Reifenrath and D. W. Korte, Effects of weathering on fabrics treated with permethrin for protection against mosquitoes. J. AM. Mosq. Control. Assoc., 5: 176-179, 1989

Curtis, C. F., J. Myamba and T. J. Wilkes, Comparison of different insecticides and fabrics for anti-mosquito bednets and curtains. Med. Vet. Entomol., 10: 1-11, 1996

Debboun, M., R. E. Coleman, P. K. Gupta and D. Strickman, Soldier acceptability of a camouflage face paint combined with DEET insect repellent. Mil. Med., 166 (9): 777-782, 2001
Deparis, X., B. Frere, M. N. Lamizana, R. Guessan, F. Leroux, P. Lefevre, L. Finot, J. M. Hougard, P. Carnerale, P. Gillet and D. Baudon, Efficacy of permethrin-treated uniforms in combination with DEET topical repellent for protection of French Military troops in cote d'Ivoire. J. Med. Entomol., 41 (5): 914-21, 2004

Deparis, X., J. P. Boutin, R. Michel and L. Galoisy Guibal, Disease vector control strategy in the French army. Med. Trop., 61 (1): 87-90, 2001

Esmsila, C., S. P. Frances and D. Strickman, Evaluation of permethrin-treated military uniforms for personal protection against malaria in northeastern Thailand. J.Am. Mosq. Control. Assoc., 10 (4): 515521, 1994

Fryauff, D. J., M. A. Shoukly, H. A. Hanafi, Y. M. Chio, K. E. Kanel and C. E. Schreck, Contact toxicity of permethrin-imperegnated militray uniforms to Culex pipiens and Phlebatomus papatasi: Effects of landering and time of exposure. J. AM. Mosq. Control. Assoc., 12, (1): 84-90, 1996

Gonzalez, J. O., A. I. Kroeger and E. Pabon, Wash resistance of insecticide-treated materials. Transactions of the Royal Society of Tropical Medicine and Hygienic. 96: 370-75, 2002

Guillet, P., R. N. Guessan, F. Darriet, M. Traore-Lamizana, F. Chander and P. Carnevale, Combined Pyrethroid and Carboamate, two-in-one' treated mosquito nets: Field efficacy against Pyrethroid-resistant Anopheles gambiae and Culex quinquefasciatus. Med. Vet. Entomol., 15:105-112, 2001

Gupta, S., S. Kumar Handa and K. Kumar Sharma, A new spry reagent for the detection of synthetic Pyrethroids containing a nitrile group on thin-layer plates. Talanta, 45: 1111-1114, 1998

Guessan, R. N., F. Darriet, J. M. C. Doannio, F. Chandre and $P$. Carnerale, Olyset net efficaly against pyrethroid resistant Anopheles gambiae and Culex quinquefasciatus after 3 years field use in cot d'Ivoire. Med. and Vet. Entomol., 15: 97-104, 2001

Harbach, R. E., The mosquitoes of the subgenus Culex in southwestern Asia and Egypt (Diptera: Culicidae). Contributions of the American Entomological Institute, 24(1): 1-240, 1988

Hossain, M. I. and C. F. Curtis, Assays of permethrinimpregnated fabrics and bioassays with mosquitoes (Diptera: Culicidae). Bull. Ent. Res., 79:299-308, 1989

Lane, R. S. and J. R. Anderson, Pressurized sprays of permethrin as a repellent and toxicant for personal 
protection against the pacific coast tick and the pajaroello tick. J. Med. Entomol., 21: 692-702, 1984

Lee, N., D. P. McAdam and J. H. Skerritt, Development of immunoassay for type II synthetic Pyrethroid. J. Agric. Food Chem., 46, 520-534, 1998

Lillie, T. H., C. E. Schreck and A.Y. Rahe, Effectiveness of personal protection against mosquitoes in Alaska. J. Med. Entomol., 25 (6): 475-478, 1988

Magill, A. J., M. Grogl, R. A. Gasser, W. Sun and C. N. Oster, Visceral infection caused by Leishmania tropica in veterans of Operation Desert Storm. N. B. Engl. J. Med., 328: 1383-1387, 1993

Romi, R., M. Peragallo, G. Sarnicola and R. Dommarco, Impregnation of uniforms with permethrin as a mean of protection of working personal exposed to control with hematophagous arthropods. Ann. Ig., 9 (4): 313319, 1997

Savage, H. and B. Miller, House mosquitoes of the U.S.A, Culex pipiens Complex. Wing Beast., 6 (2): 8-9, 1995

Schreck, C. E., Techniques for the evaluation of insect repellent: A critical review. Ann. Rev. Entomol., 22:101-9, 1977

Schreck, C. E., D. A. Carlson and D. E. Weidhaas, Wear and Aging tests with permethrin - treated cotton polyester fabric. J.Econ. Entomol., 73:451-453, 1980

Schreck, C. E. and D. L. Kline, Personal protection afforded by controlled-release topical repellents and permethrin-treated clothing against natural population of Aedes taeniorhnchus. J.Am. Mosq. Control. Assoc., 5 (1): 77-80, 1989

Schreck, C. E., G. A. Mount, D. A. Carlson, Wear and Wash persistence of permethrin used as a clothing treatment for personal protection against the lone start Tick. J. Med. J. Econ. Entomol., 19: 143-146, 1982
Schreck, C. E., K. Posey and D. Smith, Durability of permethrin as a potential clothing treatment to against blood-feeding arthropods. J. Econ. Entomol., 71:397-400, 1978

Schreck, C. E., N. Smith and D. Weidhaas, Repellents VS. Toxicants as clothing treatments for protection from mosquitoes and other Biting Flies. J.Econ. Entomol.,71: 919-922, 1978

Schreck, C. E., E. L. Snoddy and G. A. Mount, Permethrin and repellents as clothing impregnats for the lone star tick. J. Econ. Entomol., 73: 436-439,1980

Schreck, C. E., E. L. Sonddy and A. Spielman, Pressurized Sprays of permethrin or deet on military clothing for personal protection against Ixodes dammini. J. Med. Entomol., 23: 396-399, 1988

Sherma, J., Review: Determination of Pesticides by thinlayer chromatography. J. Planer Chromatogr As., 10:80-89, 1997

Sholdt, L. L., E. J. Rogers, E. J.Gerberg and C. E. Schreck, Effectiveness of permethrin - treated military uniform fabric against human body lice. Mil. Med., 154 (2): 90-93, 1989

Sholdt, L. L., C. E. Schreck, A. Qureshi and M. Iqball, Field bioassay of permethrin - treated uniforms and extended duration repellent against mosquitoes in Pakistan. J. AM. Mosq. Control Assoc., 4 (3):233236, 1988

WHO, Report of the second meeting of the global collaboration for development of pesticides for public Health (GCDPP). WHO Head Quarters, Geneva. World Helath Organization, 2000

Wood, S. A., N. Licastro, M. I. Casabe, R. Picollo, E. Zerba, Beta-Cypermethrin impregnated fabrics: A New Tactic for Triatoma Infestans Control, 1998

Zaim, M., P. S. Cranston, Checklist and Keys to the culicinae of Iran (Diptera: Culicidae). Mosq syst., 18: 233-245, 1986 